\title{
Olfactory region schwannoma: Excision with preservation of olfaction
}

\author{
Pravin Salunke, Devi Prasad Patra, Sameer Futane, Ritambhara Nada ${ }^{1}$ \\ Departments of Neurosurgery, and ${ }^{1}$ Histopathology, Post Graduate Institute of Medical Education and Research, Chandigarh, India
}

\section{ABSTRACT}

Olfactory region schwannomas are rare, but when they occur, they commonly arise from the meningeal branches of the trigeminal nerve and may present without involvement of the olfaction. A 24 year old lady presented with hemifacial paraesthesias. Radiology revealed a large olfactory region enhancing lesion. She was operated through a transbasal with olfactory preserving approach. This manuscript highlights the importance of olfactory preservation in such lesions.

Key words: Olfactory groove, olfactory preserving surgery, schwannoma

\section{Introduction}

Solitary olfactory region schwannomas are rare. ${ }^{[1,2]}$ These schwannomas commonly arise from the branches of trigeminal nerve (anterior ethmoidal) in that region, though it may arise from olfactory fila. ${ }^{[1,2]}$ Pre-operatively, olfaction may be un-involved..$^{[3]}$ It is possible to separately identify the olfactory bulb and preserve its function even in large olfactory region schwannomas making pre-operative planning of paramount importance.

\section{Case Report}

Twenty four year old lady presented with abnormal sensations on the right half of face for two months. She had no features suggestive of raised intracranial pressure and examination revealed no neurological abnormality. The olfaction was tested in details after reviewing the radiology. She was able to identify soap, coffee, clove oil and toothpaste by smelling them without visual cues. Radiology revealed a large contrast enhancing extra-axial subfrontal, olfactory region mass extending on either

\begin{tabular}{|l|l|}
\hline \multicolumn{2}{|c|}{ Access this article online } \\
\hline Quick Response Code: & Website: \\
\hline & www.ruralneuropractice.com \\
\cline { 2 - 3 } & \\
\hline
\end{tabular}

side. There were cystic areas interspersed and the contrast uptake was variegated [Figure 1a-d]. Furthermore, lack of dural enhancement differentiated it form an olfactory groove meningioma. An extended bifrontal craniotomy was made with circumferential osteotomies cut around the cribriform plate to preserve olfaction. ${ }^{[4]}$ About a cm thick mucosa was preserved ${ }^{[4]}$ The basal dura was normal, unlike meningioma. Dura was opened on either side. The lesion had a variable consistency from firm to soft and was moderately vascular. The olfactory tract was seen on either side and could be preserved. Gross total excision was achieved. Post-operatively, she had no cerebrospinal fluid leak, her symptoms of facial paraesthesias improved. On post-operative days 3 and 7 , she was not able to identify any of the objects on smelling. Six weeks later, she was able to identify soap, clove oil and coffee but failed to recognize toothpaste. Postoperative imaging showed total excision [Figure 1e and f]. Histopathology showed spindle shaped cells with elongated nuclei. A few hyalinaized vessels were seen [Figure 2a-c].Immunostaining positivity with S-100 confirmed schwannoma [Figure 2d].

\section{Discussion}

Schwannomas are benign tumors arising from the Schwann cells, usually seen along the peripheral and distal portion of the cranial nerves. The olfactory nerve does not have Schwann cells and is unlikely to develop schwannoma. It has been suggested that the origin of the tumor is from the fila olfactoria, which is known to acquire Schwann cell approximately $0.5 \mathrm{~mm}$ beyond

Address for correspondence:

Dr. Pravin Salunke, Department of Neurosurgery, PGIMER, Sector 12, Madhya Marg, Chandigarh - 160 012, India. E-mail: drpravin_salunke@ yahoo.co.uk 

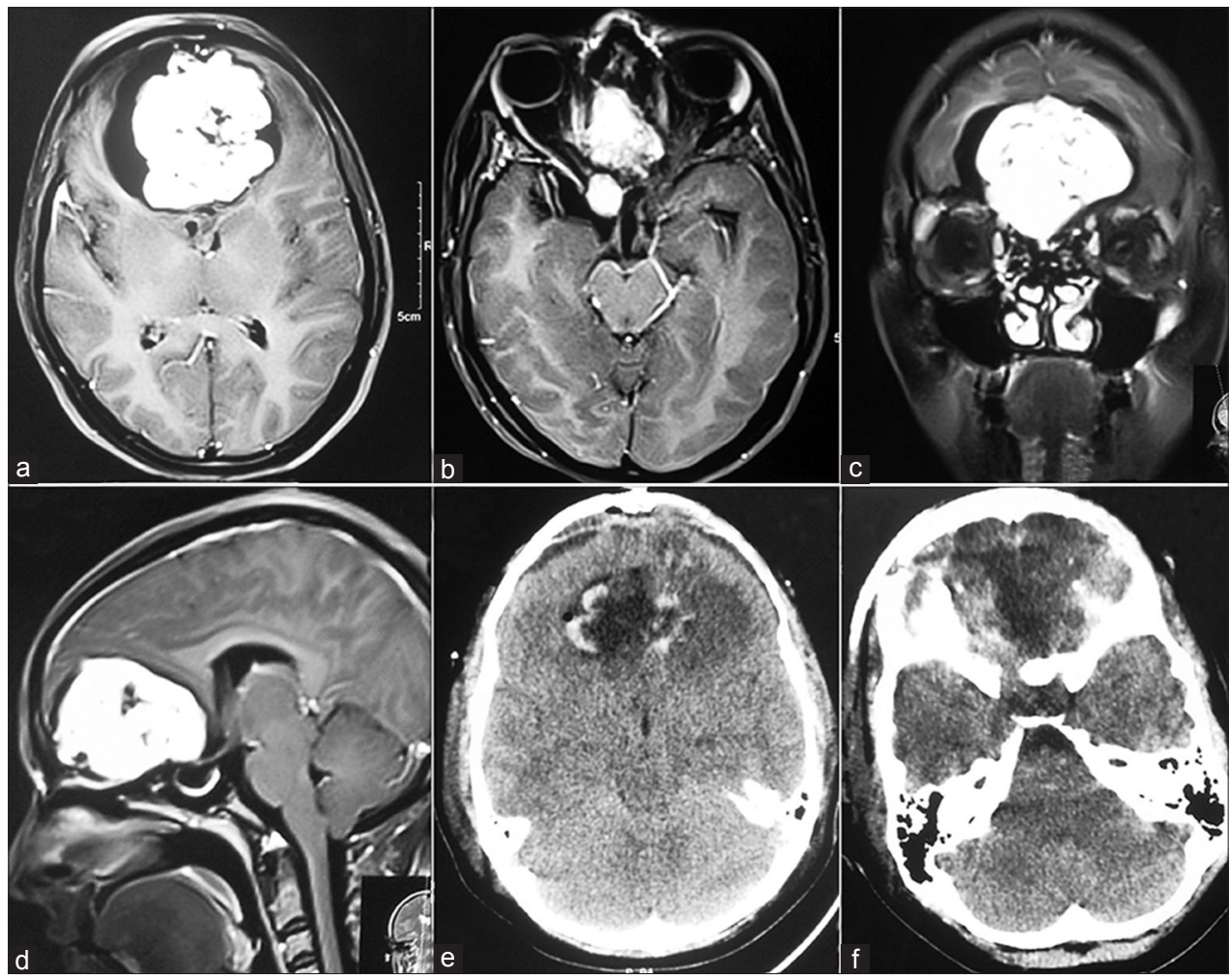

Figure 1: $(a$ and b) Axial contrast MRI showing enhancing lesion with cystic areas in basifrontal region and olfactory groove. (c) Coronal and (d) Mid Sagittal MRI showing lesion in the basifrontal region. (e and f) Post operative CT scan showing gross total excision of the lesion

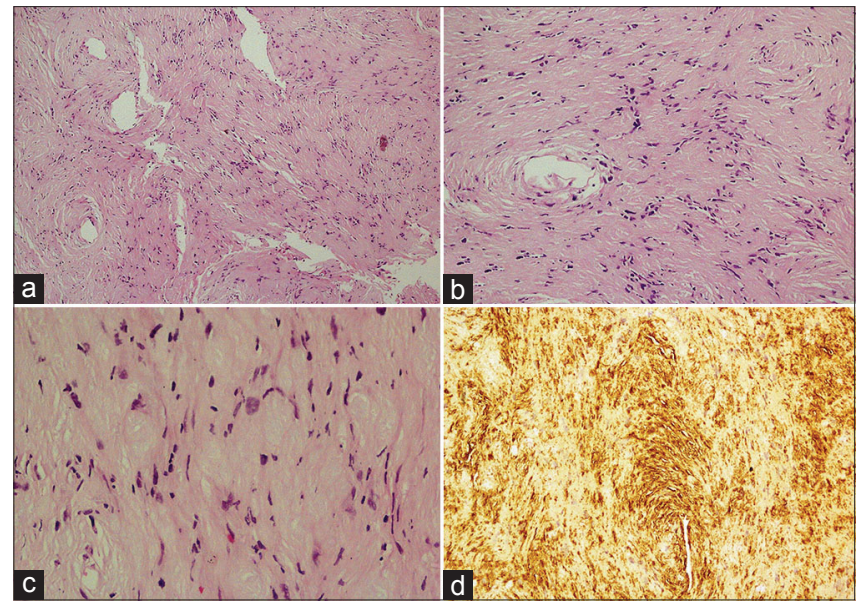

Figure 2: (a) (H and $\mathrm{E}, \times 40)$ magnification showing Hypercellular (Antoni-A) and Hypocellular (Antoni-B) areas with hyalinised blood vessels. (b) 100x magnification showing tumor cells which are ovoid to spindle shaped. (c) $200 \times$ magnification showing nuclear characteristics which are elongated, wavy with pointed ends. (d) S-100 protein immunostaining showing diffuse nuclear and cytoplasmic immunoreactivity

the olfactory bulb. The other possibility is that of a schwannoma arising from an intracranial peripheral nerve like anterior ethmoidal nerve or other branches of the trigeminal nerve. ${ }^{[1-3]}$

Our patient possibly had the tumor originating from a branch of the trigeminal nerve, giving rise to unusual symptoms of hemifacial paraesthesias. The symptoms possibly may be secondary to mechanical stretch or some sort of retrograde degeneration or demyelination. Additionally, the visualization of olfactory bulbs and tracts made its origin more likely from the trigeminal branch.

More importantly, the approach needs to be tailored in a fashion so as to preserve the olfaction. The loss of olfaction has a significant psychological impact apart from the loss of a special sense, making its preservation important. The extended bifrontal approach has the benefit of good exposure with minimal brain retraction and avoids ligation and division of superior sagittal sinus. However, this comes at the expense of loss of olfaction and the perils of CSF leak. The olfactory preserving transbasal approach circumvents these complications without compromising the benefits. ${ }^{[4]}$ Endoscopic approaches have been described; however the preservation of olfaction has not been highlighted. ${ }^{[5]}$ This report highlights not only a common pathology at an unusual site but also the importance of olfactory preserving approach for such lesions.

\section{References}

1. Figueiredo EG, Soga Y, Amorim RL, Oliveira AM, Teixeira MJ. The 
puzzling olfactory groove schwannoma: A systematic review. Skull Base 2011;21:31-6.

2. Lin SC, Chen MH, Lin CF, Ho DM. Olfactory ensheathing cell tumor with neurofibroma-like features: A case report and review of the literature. J Neurooncol 2010;97:117-22.

3. Li YP, Jiang S, Zhou PZ, Ni YB. Solitary olfactory schwannoma without olfactory dysfunction: A new case report and literature review. Neurol Sci 2012;33:137-42.

4. Feiz-Erfan I, Han PP, Spetzler RF, Horn EM, Klopfenstein JD, Kim LJ, et al. Preserving olfactory function in anterior craniofacial surgery through cribriform plate osteotomy applied in selected patients. Neurosurgery
2005;57 Suppl 1:86-93.

5. Liu JK, Eloy JA. Expanded endoscopic endonasal transcribriform approach for resection of anterior skull base olfactory schwannoma. J Neurosurg 2012;32 Suppl:E3.

How to cite this article: Salunke P, Patra DP, Futane S, Nada R. Olfactory region schwannoma: Excision with preservation of olfaction.

J Neurosci Rural Pract 2014;5:281-3.

Source of Support: Nil. Conflict of Interest: None declared. 